\title{
A SYSTEMATIC REVIEW: SOFTWARE SOLUTIONS FOR TIME- MANAGEMENT IN REMOTE WORK SETTINGS
}

\author{
Ivan Gjorgjievski ${ }^{1}$ \\ Daniela Karadakov ${ }^{2}$
}

DOI: https://doi.org/10.31410/LIMEN.2020.239

\begin{abstract}
Ever since the onset of the Internet and the rapid development in communications, a paradigm shift has been occurring between the human resources and the management systems in place. That shift has already rendered plenty of legacy management systems obsolete and ineffective. Evidently, the acceleration of data transfer speeds has produced a side effect in decreasing the location dependency of the average worker in certain industries, which in turn created a new challenge for the contemporary manager especially when dealing with remote teams and time-management of the same. This work-location decoupling meant that new systems had to be created, new studies to be introduced and plenty of modernization to the legacy control systems had to be implemented. And fast!

This paper contains a systematic review of available software solutions for time management, location independency, virtual work and work teams and will provide analytic insight.
\end{abstract}

Keywords: Time-management, Software solution, Remote work.

\section{INTRODUCTION}

7 As a resource, it cannot be archived, contained or changed but it can only be used productively and effectively. To manage time is to have developed competences in setting and achieving goals in a given time frame. Efficient time management directly corelates to the health and personal effectiveness on oneself. When control over the time is lost, then it becomes a source of stress, anxiety, depression, worsened results, behavioural changes and so on.

Time management in business terms represents the competency to determine priorities, function effectively and properly delegate (Karadakov \& Tasevska, 2021). A proper time management will enable increased productivity and efficacy, will show professionalism, will lower stress, increase improvement opportunities and in turn will support achievement of personal and professional goals.

The ever-developing technology have so far surpassed all expectations in every field. Smart phones, smart watches, tablets, social media, etc., have dramatically changed the personal and the work environment. If utilized properly, the technology undoubtedly improves all functions, which in turn improves time-management (Karadakov \& Tasevska, 2021).

There are plenty of available applications and software solutions on the market today which assists the time-management effectiveness. With their help one can drastically lower the effort

Business Academy Smilevski - BAS, Jane Sandanski 111/2, Skopje, North Macedonia

Business Academy Smilevski - BAS, Jane Sandanski 111/2, Skopje, North Macedonia 
put in to time planning, to monitor task fulfillment dynamic, to create schedules and priorities, do notify and remind for important tasks, etc. (Karadakov \& Tasevska, 2021).

An individual is able to improve time management competence through the use of technology. He or she will need to utilize the power of technology while also taking care not to became "a slave" of it. ${ }^{3}$

There is an increasing number of managers that recognize the benefits and the advancements gained with the utilization of personal digital assistants. Those may come as a small form devices or software solutions and applications that enable the archiving, exporting, importing and creating data, extrapolating information, create calendar appointments, lists, tasks, etc. At the same time, the aforementioned solutions enable collaboration between stakeholders (employees, clients, partners, managers, etc.), and collaboration on certain tasks, activities or locations. Such solutions will enable time measurement, monitoring and control over tasks, archive information and data, scheduling, reporting and improving communication.

Although there are plenty of benefits (pros) on using the technology and the technological solutions to effectively and efficiently manage time, certain shortcomings (cons) can emerge as well. The table below contains a short overview of pros and cons.

Table 1. Overview of pros and cons

\begin{tabular}{|c|c|}
\hline Pros & Cons \\
\hline Simplicity of use & Possible data-loss or data-leak \\
\hline Compactness & A solution can become expensive \\
\hline Scheduling and monitoring functionality & Can become cumbersome to use \\
\hline Archiving and extrapolating information & May come with a steep learning curve \\
\hline Search and find information functionality & $\begin{array}{r}\text { Technology advancement can render it } \\
\text { obsolete }\end{array}$ \\
\hline Flexibility and reporting & $\begin{array}{r}\text { May not be accepted by older generation } \\
\text { workers }\end{array}$ \\
\hline
\end{tabular}

\section{SYSTEMATIC OVERVIEW OF SOFTWARE SOLUTIONS}

The process of digitalization, especially accented during these pandemic times, for some organizations meant significant restructuring of certain business processes, where some managers noted that the paradigm of distrust in technology is slowly fading away. This has become apparent mostly in the field of time management and replacing human efforts with digital solutions. As stated previously, the market offers a plethora of software solutions for time management and monitoring, and as such, this paper will contain their research on the 10 most developed and recognized software solutions in 2020. All of the software solutions will be assessed in accordance with the aforementioned pros and cons and graded on the provided scale. The authors concur that all software solutions have the core functionalities implemented such as:

- Scheduling, monitoring and control of projects, activities, processes and tasks,

- Time-monitoring per task, user, location and project,

3 Karadakov, D., \& Tasevska, G. (2021). Personal management (In publishing). Skopje: Business Accademy Smilevski - BAS. 
- User creation and administration,

- Calendar attachments,

- Data storage and archiving functionalities,

- Reporting capabilities.

A table of criteria that stem from the pros and cons mentioned previously is created and will be use as a measuring tool. The assembly of software solutions will be assessed in accordance with the criteria and rated on a scale of compliance. The established measuring criteria is as follows:

- Simplicity of use (UX/UI design, intuitiveness, etc.),

- Wearables applicability (Feature that enables use with smartwatches and other wearable tech),

- Flexibility (Adjusting the software interface to look and work as per needs or wants),

- Collaborative functionality (Messaging or chat between stake holders, ability to create teams and combine tasks/activities/projects, etc),

- Price of use or purchase,

- Data security and GDRP compliance,

- Reporting.

All of the software solutions will be graded by the scale below in accordance to the established criteria. The scale is as follows:

- FC - Full compliance (+2 points),

- PC - Partial compliance (+1 point),

- N/A - Not available or not applicable (-1 point),

- $\mathrm{X}$ - No data (No points).

According to one of the leading IT industry web authorities PCMAG, the best software solutions on the market are as follows:

Table 2. Best software solutions on the market

\begin{tabular}{|l|l|c|}
\hline Software solution & Price (lowest price option) & $\begin{array}{l}\text { PC MAG } \\
\text { Score }\end{array}$ \\
\hline BQE Core & $27.90 \$ /$ month/user & 4.5 \\
\hline TSheets & $10 \$ /$ month/user & 4.5 \\
\hline Zoho Projects & $5 \$ /$ month/user & 4.5 \\
\hline HubStaff & \$\$/month/user & 4.0 \\
\hline Time Doctor & $10 \$ /$ month/user & 4.0 \\
\hline VeriClock & $15 \$ /$ month & 4.0 \\
\hline Wrike & $24.8 \$ /$ month/user & 4.0 \\
\hline MavenLink & $39 \$$ month/user & 3.5 \\
\hline FunctionFox & $35 \$ /$ month initial payment + & 3.0 \\
\hline TimeSolv & $5 \$ /$ month/additional users & 3.0 \\
\hline
\end{tabular}

Source: (Martinez \& Horowitz, 2020) 
The matrix table correlating the given criteria with assessments per software solution is as follows:

Table 3. Matrix table correlating the given criteria with assessments per software solution

\begin{tabular}{|c|c|c|c|c|c|c|c|}
\hline \multirow[b]{2}{*}{ Software } & \multicolumn{7}{|c|}{ Criteria } \\
\hline & 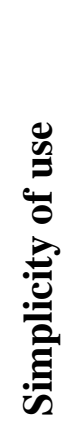 & 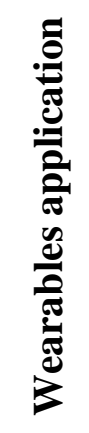 & 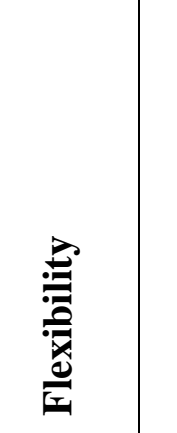 & 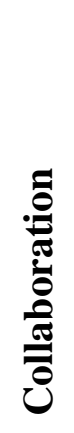 & 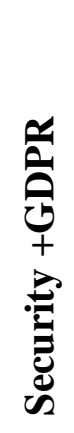 & 象 & 通 \\
\hline BQE Core & $\mathrm{FC}$ & $\mathrm{PC}$ & $\mathrm{PC}$ & $\mathrm{FC}$ & $\mathrm{FC}$ & $\mathrm{FC}$ & $\mathbf{1 0}$ \\
\hline TSheets & $\mathrm{FC}$ & $\mathrm{PC}$ & $\mathrm{FC}$ & $\mathrm{PC}$ & $\mathrm{FC}$ & $\mathrm{FC}$ & 9 \\
\hline Zoho Projects & $\mathrm{FC}$ & $\mathrm{FC}^{*}$ & $\mathrm{FC}$ & $\mathrm{FC}$ & $\mathrm{FC}$ & $\mathrm{FC}$ & 12 \\
\hline HubStaff & $\mathrm{FC}$ & $\mathrm{PC}$ & $\mathrm{PC}$ & $\mathrm{PC}$ & $\mathrm{FC}$ & $\mathrm{PC}$ & 8 \\
\hline Time Doctor & $\mathrm{PC}$ & $\mathrm{PC}$ & $\mathrm{PC}$ & $\mathrm{PC}$ & $\mathrm{FC}$ & $\mathrm{FC}$ & 8 \\
\hline VeriClock & $\mathrm{PC}$ & $\mathrm{PC}$ & $\mathrm{FC}$ & $\mathrm{PC}$ & $\mathrm{FC}$ & $\mathrm{FC}$ & 9 \\
\hline Wrike & $\mathrm{FC}$ & $\mathrm{PC}$ & $\mathrm{FC}$ & $\mathrm{FC}$ & $\mathrm{FC}$ & $\mathrm{FC}$ & 11 \\
\hline MavenLink & $\mathrm{PC}$ & N/A & $\mathrm{PC}$ & $\mathrm{PC}$ & $\mathrm{FC}$ & $\mathrm{FC}$ & 6 \\
\hline FunctionFox & $\mathrm{FC}$ & $\mathrm{PC}$ & $\mathrm{PC}$ & $\mathrm{PC}$ & $\mathrm{FC}$ & $\mathrm{FC}$ & 9 \\
\hline TimeSolv & $\mathrm{PC}$ & $\mathrm{PC}$ & $\mathrm{PC}$ & $\mathrm{PC}$ & $\mathrm{FC}$ & $\mathrm{FC}$ & 8 \\
\hline & & & Legend: & $\begin{array}{l}\text { FC } \\
\text { PC } \\
\text { N/A } \\
\text { app } \\
\mathbf{X}\end{array}$ & $\begin{array}{l}1 \text { cor } \\
\text { tial c } \\
\text { Not } \\
\text { e }(-1 \\
\text { ata }\end{array}$ & $\begin{array}{l}\text { nce ( } \\
\text { iance } \\
\text { ailabl } \\
\text { t) } \\
\text { oints }\end{array}$ & $\begin{array}{l}\text { ints) } \\
\text { point) } \\
\text { r not }\end{array}$ \\
\hline
\end{tabular}

*through separate application.

The results show that most of the solutions comply more-or-less with the given criteria and at the beginning a credit is due in the cyber security and the GDPR compliance criteria of all the solutions. According to the table, more than half of the solutions (6/10) are compliant with our assessment of simplicity of use. A certain degree of obsolete and unintuitive interfaces were monitored at the rest of the solutions.

Wearable application was noted only through a specific, additional solution for only one of the solutions, yet all solutions (except one) offer a smartphone integration of some kind. Additionally, it was noted that all of the solutions offer a certain degree of integration within popular calendar applications which in turn can be utilized by the majority of the wearable technology.

Flexibility as criteria assesses the software capabilities and options for adjusting the interface, reports, templates, etc., in accordance to the needs of the business, manager, process, project or task. It is noted that all of the software solutions measured, are having this functionality within the core, however certain number of them (6/10) require knowledge of higher computer skills such as programming or UI/UX competences. Additionally, the majority of the software 
solutions required higher tier subscriptions to enable the full flexibility options which may in turn become costly and expensive for a small to mid size business.

Only a small percentage (3/10) of the software solutions were featuring means of direct communication (chat tools, message boards, task messages and comments, etc.). The rest of them $(6 / 10)$ were offering either communication within rigid structures (task or period comments only or logs) or no communication between stakeholders whatsoever (1/10). Yet, as these solutions are intended for lessening the impact of planning, organization and monitoring on the time itself, they all offer a specific frame of collaboration within a project, activity, task, function or location, therefore it can be concluded that all satisfy the criteria either partially or fully.

It is commendable that $10 / 10$ of the software solutions have fully implemented cyber and data security and GDPR protocols compliance.

Reporting is a key feature for the core of all the software solutions of this kind, as in the end, a manager would like to be able to monitor, control and extrapolate conclusions on the data provided and generated by the completion of tasks, time frame compliance and expected results. There is an easily noticed focus on the reporting features which lead to increased requirements for flexibility, yet some of the solutions offer reporting flexibility as part of higher tier subscriptions and others require certain degree of programming skills. Yet there is a $9 / 10$ compliance with this criteria.

The table shows that one of the solutions that have been assessed is one of the most criteria compliant software solutions.

\section{FUTURE RESEARCH DIRECTIONS}

Core management functions are planning, organization, control and leadership of people, teams and processes. As with any organizational changes, the pandemic has accented the development and digital restructuring of the business processes, which in turn resulted in increased popularity of software solutions. The market offers a huge spectrum of software solutions that can aid the contemporary manager, however the organizational wisdom cautions: Even the most expensive and extravagant software solution will prove cumbersome and an obstacle instead of assistance or lessening the work if not utilized properly.

With the rapid development of technology, the need for future research in aspects of bridging the work and software is further accentuated. One of the key filters within the research and implementation in the business processes should be the management team. As noted in the book Operations Management, 7th Ed by (Slack, Brandon-Jones, \& Johnston, 2013) all managers need to be able to comprehend and implement the technology in three stages as follows:

Stage 1: Understand the process technology,

Stage 2: Evaluate the process technology,

Stage 3: Implement the process technology.

Therefore, all managers need to be able to understand how a software solution will work, will help or will optimize and streamline the processes. Next, the managers ought to be able to evaluate the impact the software solution is or will be creating by its utilization and at the end, 
it requires them to be able to implement it within the business processes, people, teams and projects.

\section{CONCLUSION}

A key factor in achieving organizational goals is the time itself. Efficient time management is done by the utilization of the contemporary technology advancements and solutions that exist on the market. The use of devices or software solutions bring certain pros and cons which were touched upon on the pages of this paper. What is important for the modern organizations is to be able to evaluate its needs and find or create a software solution to comply with their organizational goals or objectives. Based on the results and the discussion in this paper, a conclusion can be extrapolated.

This paper offers a systemic overview on the digital tools present and established on the market for time-management assistance and improvement. The overview should be able to assist any organization in their decision making efforts on which software solution would work best, what to look for in such a tool and what is there to be understood and expected by utilizing such a technology. The overview is expanded further in the final paragraphs by a notice on what should the modern managers understand, do and do not do when dealing with these technologies.

\section{REFERENCES}

Hoover, J. (n.d.). Time management - Set Priorities To Get The Right Things Done. Harper Collins E-books.

Karadakov, D., \& Tasevska, G. (2021). Personal management (In publishing). Skopje: Business Accademy Smilevski - BAS.

Mancini, M. (2003). Time management. New York: McGraw-Hill.

Martinez, J., \& Horowitz, B. T. (2020). The Best Time Tracking Software for 2021. From PCMag: https://www.pcmag.com/picks/the-best-time-tracking-software

Slack, N., Brandon-Jones, A., \& Johnston, R. (2013). Operations management (7th ed.). Harlow, United Kingdom: Pearson Education Limited.

Tracy, B. (2013 ). Time management. New York: Amacom. 